\title{
EMISSION REDUCTION VIA SUPPLY CHAIN COORDINATION
}

\section{January 2018}

\begin{abstract}
This paper examines the environmental impact of potential coordination on supply chains. A decentralized two-node supply chain is studied, in which one node is a buyer ordering from a second node, who is a supplier operating under the lot-for-lot policy. The supplier is allowed to use a quantity discount to manipulate the buyer's decision reducing both his individual cost and system's operational costs. This results in decreasing the frequency of deliveries. We demonstrate that environmentally friendly policies could be also cost saving. The crucial factor about the environmental benefits is the total distance travelled rather than the vehicle loads. We establish the magnitude of the environmental benefits using numerical examples under specific operational parameters. Complete and incomplete information cases are investigated, where the buyer and the supplier make their decisions to optimize their own business operations.
\end{abstract}

Keywords: Road Transportation, Emission Model, Sustainability, Supply Chain.

\section{Introduction}

Environmental considerations in supply chain management have become more and more important for many firms as they are imposed mainly by new legislation as well as the need to improve further their environmental profile for their clientele. Especially, during the last two decades both practitioners and academics have paid attention to the improvement of the environmental impact on supply chains, introducing the 'Green Supply Chain 
Management' term. The firms have been pushed by consumers and legislators to redesign their processes and mitigate the negative environmental effects of their activities Neto et al. 2008). Many leading firms such as IBM, Walmart, and Tesco have adopted strategies to reduce carbon emissions and fuel consumption (Sundarakani et al., 2010). Also they use performance indicators to quantify the environmental effects of different business models (Hervani et al., 2005).

The fundamental question in supply chain management remains, how the different decision makers could act in a decentralized manner, but still reduce their individual costs. In addition to the classical models for cost minimization, the research efforts in recent years focused on additional aspects such as social impact including traffic congestion (Shao et al., 2016), the number of accidents and the road safety considerations (Sarkis et al., 2010), as well as environmental impact such as $\mathrm{CO}_{2}, \mathrm{CO}, \mathrm{HC}, \mathrm{NO}_{\mathrm{x}}$, and $\mathrm{PM}$ emissions (Sundarakani et al., 2010). Many studies try to re-design a supply chain to mitigate all or most of the above consequences; an indicative example is provided by Cachon (2014) showing how the retail store density affects emissions. According to Cachon (2014) if a retailer designs the layout of his/her network, focusing only to minimize the operational costs this can significantly increase emissions. Thus, there are cases in which the economic and the environmental costs are not be aligned.

Ideally, company policies should minimize the environmental costs whilst minimizing the total supply chain cost. Our objective is to examine the environmental impact of logistics activities on a two-node supply chain developing a coordination mechanism to minimize at the same time the operational cost.

Various models are proposed and analysed to reduce the costs in a supply chain. A basic question is under which circumstances it is possible to apply a decentralized model and well approximate or even obtain the optimal solution of a centralized model. This, in fact, is supply chain coordination. In a centralized model all decisions are made by a single decision maker; thus, the minimum total cost is achieved. This is the theoretical ideal situation in terms of cost reduction, but it is almost infeasible to achieve it under 
free market conditions, and independent, decentralised decision makers. This happens because individual nodes of the supply chain are decision makers with competing objectives, conflicting preferences, and private information.

A centralized solution in a decentralized approach means that the individual incentives of each decision maker are aligned with the incentives of the whole system. This could happen if the decision makers coordinate their individual decisions and share their private information (Viswanathan and Wang, 2003). The most common solutions to achieve coordination in the literature are: i) nodes' signing of a contract and then all nodes making subsequent decisions in line with the contract parameters Corbett et al. 2004) and ii) nodes' participating in a coalition and acting as a single decision maker (Nagarajan and Sosic, 2008).

The literature on supply chain coordination is vast; however, the interrelationship between supply chain coordination and environmental sustainability still needs further investigation. Therefore, our objective is to quantify the environmental benefits of a potential coordination between two nodes. More specifically, we examine the environmental impact of logistics activities because transportation is a key factor for the competitiveness of the world economy and a considerable amount of research has been carried out to optimise logistics systems. The growing freight transport (RITA, 2010) has an increasing level of negative impact; such as traffic congestion, air and noise pollution, and threat to road safety due to higher number of vehicles. It is well known that the transport sector has the fastest growing emissions with the road transport subsector being the largest contributor to global warming through $\mathrm{CO}_{2}$ emissions (EC, 2011; EPA, 2015). Especially, the urban freight traffic accounts for about 10-15\% of kilometres travelled and emits approximately $6 \%$ of all transport-related greenhouse gas emissions (CIVITAS, 2015). Therefore, a potential reduction of total kilometres travelled will have a significant impact on the environment and the society.

Coordination leads to larger order quantities, reducing the frequency of deliveries between the nodes. This means less total distance travelled; i.e. less trips between the 
nodes, but with more load. Thus, it is not sufficient to consider only the total kilometres travelled as a performance indicator but also to use emission models to quantify the environmental impact of overall transportation activities.

This work examines the environmental impact of road transportation on supply chains. To the best of our knowledge, this is the first research study analysing the role of interrelationship between supply chain coordination and environmental sustainability. The main contribution of our work is twofold: i) to show that environmentally friendly policies are also cost saving, and ii) to quantify the impact of supply chain coordination on the environment in terms of fuel consumption and emissions, applying an emission model.

The remainder of the paper is organized as follows: Section 2 describes the emission calculation model that will be used in this work. Section 3 presents a specific two-node supply chain, defines the modelling approach adopted for the decentralized solution, and gives an analytical expression of the reduction in the number of trips between the nodes under complete and incomplete information. Section 4 provides numerical experiments to evaluate the environmental effects of a potential coordination. Section 5 summarizes the conclusions and sets questions for future research.

\section{Emission Model}

Our objective is to examine the environmental impact of potential coordination on a supply chain, focusing on fuel consumption and emissions. An emission model is needed to quantify the environmental impact of transportation activities between the nodes. There are several emission models that can be categorised into macroscopic and microscopic models. Emission models can be complex and diverse; thus, some knowledge of their fundamental functionality is essential. The calculation of energy consumption and emissions are directly linked to each other. There are many factors such as driving behaviour, road conditions, and vehicle conditions that can affect fuel consumption and subsequently emis- 
sions. However, it may be difficult to fully reflect all these factors in an emission model (Demir et al. 2014). Many models can only incorporate a small number of input factors. In general, the emission calculation models are categorized as follows:

1. Aggregated emission factor models. These are the simplest models with only a single emission factor being used to represent a specific type of vehicle and type of road, i.e. urban, rural or highway (COST, 2006).

2. Average speed models (non-adjusted and adjusted). These models are based on the principle that the average emission factor for a certain pollutant and a specific type of vehicle depends on the average speed of that vehicle. Therefore, emissions can be calculated by taking into consideration only the average speed. Then an emission factor is stated in terms of the grams per travelled kilometers $(\mathrm{g} / \mathrm{km})$. Adjusted models on the other hand use a correction factor to reconstruct the speed profile by estimating fractions of time spent during cruising, acceleration, deceleration, and idling to incorporate the effect of traffic congestion (Boulter et al., 2007).

3. Traffic situation models. This category incorporates both speed and cycle dynamics into emission estimations through traffic situation modelling, where the cycle average emission rates are correlated with various driving cycle parameters, such as: load, slope or gearshift strategies Ajtay, 2005).

4. Multiple linear regression models. These models employ a weighted-leastsquares multiple regression approach to modeling emissions, based on the data from tests with a large number of different vehicle types and a variety of driving cycles, usually more than 50 different combinations of vehicle types and driving cycles Smit et al., 2007).

5. Modal models. These models are based on factors that are allocated to the specific modes of vehicle operation encountered during a trip. In the simplest type of a modal model, the vehicle operation is defined in terms of a relatively small number of modes. Several different terms have been used to describe more detailed types of models, including 'instantaneous' which is the most well-known and most 
frequently used (de Haan and Keller, 2000), 'microscale', 'continuous' and 'on-line' (Boulter et al., 2007).

In this work, the emission model is the one used by COPERT. We have chosen COPERT's model first and foremost because it balances the need for detailed emission calculations with the use of few input data; only vehicle speed and fleet utilization. Furthermore, COPERT's model is continually updated and has been selected by European Environment agency as a base for the EMEP/EEA air pollutant emission inventory guidebook (EEA, 2016).

COPERT's model is an average speed model (Faris et al., 2011) which estimates emissions of all major air pollutants $\mathrm{NO}_{\mathrm{x}}, \mathrm{CO}, \mathrm{HC}, \mathrm{PM}$, and the fuel consumption, produced by six different main vehicle categories: passenger cars, light-duty vehicles, heavy-duty vehicles, buses, mopeds and motorcycles. For each category of emissions, one or more types of vehicles are defined, based on the engine size, and a technology is associated with each vehicle category and type (conventional, Euro V, etc.). The first version of COPERT software was published in 1989 (Park et al., 2016). COPERT 5 version 5.0 (May 2017) is the latest release and can be downloaded as a non-commercial software offered by Emisia SA. Supported by the European Environment Agency, COPERT is designed to predict the annual national emission inventories of European countries Achour and Olabi, 2016). Twenty-two EU member states use the model with their official road transport data and COPERT holds national databases of comprehensive emission factor inventories for over 240 vehicle categories including vehicles types, fuel types, emission standards, engine capacity, and maximum load (Cen et al., 2016).

We assume that the product is transported by heavy-duty vehicles. We made this assumption because heavy-duty vehicles are responsible for $25 \%$ of the $\mathrm{CO}_{2}$ emissions from road transport and approximately $6 \%$ of total emissions in the EU (EC, 2015). According to the last version of COPERT, the emission factors: $\mathrm{CO}, \mathrm{HC}, \mathrm{NO}_{\mathrm{x}}, \mathrm{PM}$, in $\mathrm{g} / \mathrm{km}$, and fuel consumption $(\mathrm{g} / \mathrm{km})$ are functions of vehicle speed, $V$, measured in $\mathrm{km} / \mathrm{h}$ while the 
feasible range about the speed is from $5 \mathrm{~km} / \mathrm{h}$ up to $85 \mathrm{~km} / \mathrm{h}$ :

$$
E F(V)=\frac{a V^{2}+b V+c+d / V}{e V^{2}+f V+g}, V \in[5,85]
$$

where $a, b, c, d, e, f$ and $g$ are parameters of the model with constant values estimated according to the utilization of the vehicle. $E F(V)$ in Equation 1 represents the following emission factors $\mathrm{CO}, \mathrm{HC}, \mathrm{NO}_{\mathrm{x}}, \mathrm{PM}$, and fuel consumption in $\mathrm{g} / \mathrm{km}$. Indicatively, we present in Table 8 (Appendix) the values for the parameters $a, b, c, d, e, f$ and $g$ that are estimated by COPERT's model for emission factors $\mathrm{CO}, \mathrm{HC}, \mathrm{PM}, \mathrm{NO}_{\mathrm{x}}$, and fuel consumption of a EURO VI heavy duty-vehicle at load levels: 0\%,50\% and 100\%.

The parameter values are available only for $0 \%, 50 \%$ and $100 \%$ load; thus, we estimate all other intermediate values using linear regression. It is also important to be able to examine emissions across applicable values of fleet utilization, as the coordination affects the load of trucks, and hence the utilisation. Based on the fleet utilization and the total distance travelled, we quantify the environmental benefits. In our study we consider also many vehicle speeds which indicate different conditions of road transport; such as urban and highway. Thus, we show how the average speed affects the environmental performance of a potential coordination.

For instance, the fuel consumption is a function of the vehicle load $x$ as a percentage (i.e. $x \in[0,100])$ and can be calculated by the following functions of vehicle speed using linear regression:

$$
F C(x)= \begin{cases}632.84+2.54 x, & \text { if } V=5 \mathrm{~km} / \mathrm{h}\left(r^{2}=0.98\right) \\ 454.38+2.2 x, & \text { if } V=10 \mathrm{~km} / \mathrm{h}\left(r^{2}=0.998\right) \\ 284.71+1.77 x, & \text { if } V=20 \mathrm{~km} / \mathrm{h}\left(r^{2}=0.999\right) \\ 224.8+1.45 x, & \text { if } V=30 \mathrm{~km} / \mathrm{h}\left(r^{2}=0.999\right) \\ 179.9+1.07 x, & \text { if } V=50 \mathrm{~km} / \mathrm{h}\left(r^{2}=0.999\right) \\ 156.6+0.8 x, & \text { if } V=80 \mathrm{~km} / \mathrm{h}\left(r^{2}=0.999\right) .\end{cases}
$$


We calculate Equation 2, assuming that the regression model for interpolating fuel consumption from the three calculated parameter levels for $0 \%, 50 \%$, and $100 \%$ loads is valid. Based on Equation 2, we are able to conduct experiments for all the possible truck utilizations (i.e. not only under $0 \%, 50 \%$, and $100 \%$ loads) and quantify the environmental impact of a coordination mechanism.

Therefore, we use a linear regression equation for the examined emission factors $\mathrm{CO}, \mathrm{HC}, \mathrm{PM}$, and $\mathrm{NO}_{\mathrm{x}}$ to estimate them for any given load factor. We distinguish the trips between the nodes into two categories: i) the trips from the supplier to the buyer with load, and ii) the return trips from the buyer to the supplier with a load factor of $0 \%$ since the buyer is only receiving goods but not sending back anything to the supplier.

The $\mathrm{CO}_{2}$ emission factor is calculated based on the amount of fuel consumed and the type of fuel. It is common in the literature to convert fuel consumption into emissions by multiplying the amount of fuel consumed by an emission factor (Szeto et al., 2012). In Table 1, we present the coefficients that convert the fuel consumption to $\mathrm{CO}_{2}$ emissions for different types of fuel.

Table 1: Emission factor $\mathrm{CO}_{2}(\mathrm{~g})$ for $1 \mathrm{~g}$ of fuel, Source: EEA (2016)

\begin{tabular}{|c|c|c|c|c|c|c|c|}
\hline Type & Gasoline & Diesel & LPG & CNG & E5 & E10 & E85 \\
\hline Coefficient & 3.180 & 3.140 & 3.017 & 2.750 & 3.125 & 3.061 & 2.104 \\
\hline
\end{tabular}

\section{Coordination Mechanism}

We consider a two-node supply chain with one supplier, denoted by $S$, producing and supplying a single product to a buyer, denoted by $B$, who orders and stores the same product in fixed quantities. The nodes interact with each other because we assume no alternatives for external interaction exist. We also assume that the annual market demand, denoted by $D$, of the single product is constant, exogenously defined and known to both nodes (Corbett, 2001), since we examine only the operational cost. As the market demand is constant, shortages or backorders are not allowed (Chen et al., 2014). 
Both nodes are risk neutral and rational, minimizing their costs without considering the system optimality. The buyer faces the Economic Order Quantity (EOQ) model; i.e. she decides the order quantity $Q>0$ taking into account a setup (corresponding to the ordering) and a holding cost, denoted by $K_{B}$ and $H$, respectively. The supplier does not own a warehouse, nor can accommodate inventory at other premises; thus, he works under the lot-for-lot policy. As a result, completed lots are directly forwarded to the buyer's warehouse. It is beyond the scope of this work, to address how the buyer supplies her local network. Furthermore, there are several works, such as Bektas and Laporte (2011), addressing the problem of visiting many points examining cost and distance reduction, and environmental benefits. In this work, we investigate two cases in which the nodes make their decisions. First the case of complete information and then a more realistic case where the buyer possess private information about the holding cost.

\subsection{Complete Information}

Under the complete information case, buyer's annual cost is a function of order quantity $Q$ (i.e. buyer's decision) and can be expressed as: $C_{B}(Q)=K_{B} D / Q+H Q / 2$, where the minimum value is $\sqrt{2 K_{B} D H}$ and is achieved when she selects $Q_{B}^{*}=\sqrt{2 K_{B} D / H}$ as order quantity. The supplier does not have the opportunity to keep inventory and therefore works under the lot-for-lot policy. The supplier has a setup cost, denoted by $K_{S}$, for each order received from the buyer and supplier's annual cost is a function of the buyer's decision; i.e. order quantity $Q$, and is expressed as $C_{S}(Q)=K_{S} D / Q$. Note that, the supplier is not a decision maker and under the assumption that buyer is a rational node, i.e. she decides $Q_{B}^{*}$, the supplier's cost is $C_{S}\left(Q_{B}^{*}\right)=K_{S} \sqrt{D H / 2 K_{B}}$. The supplier is able to analyse and foresee buyer's optimal decision since all parameters, $D, K_{B}, K_{S}$ and $H$, are constant and known to both nodes. It is obvious that supplier prefers large order quantities because his cost is a decreasing function of the order quantity.

To coordinate the chain, the supplier is allowed to provide a quantity discount. This makes him a decision maker and via this discount he can motivate the buyer to order 
a higher quantity and consequently reduce his costs. Quantity discounts are selected as a means for coordinating the supply chain and they are widely used in practice because they do not require additional information or physical flow between the nodes beyond the initial transaction (Burnetas et al. 2007). An indicative example is H. J. Heinz Company, which uses quantity discounts to reduce operational costs Altintas et al. 2008). Note that, the total supply chain cost $\left(K_{B}+K_{S}\right) D / Q+H Q / 2$; i.e. the sum of the buyer's and the supplier's cost, is minimized when the order quantity is equal to $Q_{J}^{*}=\sqrt{2\left(K_{B}+K_{S}\right) D / H}>Q_{B}^{*}$; so, a higher order quantity is also aligned with the system's objectives.

It is well known in the literature that the supplier could design a quantity discount to coordinate the supply chain and secure all the gains for himself in the case of complete information; paying the buyer the minimum discount just to induce her to order the quantity $Q_{J}^{*}$ (Corbett, 2001). According to the design mechanism theory (Fudenberg and Tirole, 1991), it is sufficient to consider discount policies with a quantity-price pair $(X, Y)$, which is the supplier's decision in this case, i.e. if the buyer orders a quantity equal to $X$, she will receive a discount $Y$ from supplier. This means that the discount is valid if and only if the retailer orders the quantity equal to $X$ and not when $Q>X$. Therefore, a Stackelberg game where the supplier is the leader and the buyer is the follower emerges as the buyer acts after having observed the supplier's decision (quantity discount).

According to Zissis et al. (2015) supplier has an incentive to provide the following quantity-price pair to minimize his cost: $\left(Q_{J}^{*}, Y_{J}^{*}\right)$; i.e. to provide a discount equal to $Y_{J}^{*}=K_{B} D / Q_{J}^{*}+H Q_{J}^{*}-\sqrt{2 K_{B} D H}$ if the buyer orders $Q_{J}^{*}$. It is important that buyer is free to decide the order quantity that minimizes her cost. Therefore, the buyer changes her order quantity from $Q_{B}^{*}$ to $Q_{J}^{*}$ and takes the discount if and only if she has at least the same cost. Table 2 presents buyer's, supplier's and the total system cost, when buyer decides without any discount and under the discount $\left(Q_{J}^{*}, Y_{J}^{*}\right)$.

The term $D / Q$ is interpreted as the number of trips for delivering the product between the nodes over a year, when the lot size is $Q$. We use the particular case where 
Table 2: Nodes and total system costs without $\left(Q_{B}^{*}\right)$ and with $\left(Q_{J}^{*}\right)$ a discount

\begin{tabular}{|c|c|c|c|}
\hline Lot size & Buyer & Supplier & Total system \\
\hline$Q_{B}^{*}$ & $\sqrt{2 K_{B} D H}$ & $K_{S} \sqrt{D H / 2 K_{B}}$ & $\left(2 K_{B}+K_{S}\right) \sqrt{D H / 2 K_{B}}$ \\
\hline$Q_{J}^{*}$ & $\sqrt{2 K_{B} D H}$ & $\sqrt{2 D H}\left(\sqrt{K_{S}+K_{B}}-\sqrt{K_{B}}\right)$ & $\sqrt{2\left(K_{B}+K_{S}\right) D H}$ \\
\hline
\end{tabular}

the buyer decides her order quantity without any discount from the supplier $\left(Q_{B}^{*}\right)$ as a benchmark in order to measure the potential benefits from the coordination. Equation 3 is used to measure the percentage reduction in the number of trips $(I)$ :

$$
I=\frac{D / Q_{B}^{*}-D / Q}{D / Q_{B}^{*}} \cdot 100 \%
$$

In the case of complete information where coordination is feasible; i.e. the order quantity is equal to $Q_{J}^{*}$, the percentage reduction in the number of trips per year to satisfy the demand is equal to $\left(1-\sqrt{K_{B} /\left(K_{S}+K_{B}\right)}\right) \cdot 100 \%$. It can be clearly noticed from this result that the percentage of improvement is higher for larger values of the supplier's setup cost $K_{S}$. This effect is consistent with our intuition, as it is related to the supplier's higher setup cost which drives the solution to higher order quantities.

\subsection{Incomplete Information}

In this case, we assume that the buyer has private information about the holding cost $H$, while the other parameters: $D, K_{B}$ and $K_{S}$ are constant and known to both nodes. According to Lovejoy (2006) continuous asymmetries are not very realistic in applications compared to discrete asymmetries. Therefore, buyer's private information $H$ is modelled as a discrete random variable that could take two values; a low holding cost $h_{L}$, which occurs with probability $p$, and a high holding cost $h_{H}$, which occurs with probability $1-p$ where $h_{H}>h_{L}$. This could be interpreted as that the buyer may store inventory at privately owned warehouses (low cost) or at the customs location (high cost).

A common way to model incomplete information is that the buyer learns the real value of the holding cost as soon as the game starts, while the supplier is aware of only the 
prior probability assessments of the low and the high values. According to the Bayesian formulation (Fudenberg and Tirole, 1991), the buyer can be either type- $L$ or type- $H$, and her cost function becomes $C_{B, L}(Q)=K_{B} D / Q+h_{L} Q / 2$ and $C_{B, H}(Q)=K_{B} D / Q+h_{H} Q / 2$, respectively. When the supplier does not provide any discount, the buyer optimizes her costs by ordering $Q_{B, L}^{*}=\sqrt{2 K_{B} D / h_{L}}$ if she is type- $L$ and $Q_{B, H}^{*}=\sqrt{2 K_{B} D / h_{H}}$ if she is type- $H$. This results in the costs presented in Table 3 .

Table 3: Nodes and system costs with type- $L$ and type- $H$ buyer, no discount

\begin{tabular}{|c|c|c|}
\hline Annual Costs & type- $L$ & type- $H$ \\
\hline Buyer & $\sqrt{2 K_{B} D h_{L}}$ & $\sqrt{2 K_{B} D h_{H}}$ \\
\hline Supplier & $K_{S} \sqrt{D h_{L} / 2 K_{B}}$ & $K_{S} \sqrt{D h_{H} / 2 K_{B}}$ \\
\hline System & $\left(2 K_{B}+K_{S}\right) \sqrt{D h_{L} / 2 K_{B}}$ & $\left(2 K_{B}+K_{S}\right) \sqrt{D h_{H} / 2 K_{B}}$ \\
\hline
\end{tabular}

The supplier could use the quantity discount as a screening device to induce the buyer to reveal her private information in line with the Revelation Principle, (Myerson, 1991). Thus, the supplier can manipulate buyer's decision and the node's objectives could be aligned with the system's objectives. In this case, according to the design mechanism theory, it is sufficient to consider only quantity discount mechanisms $m$ with two quantityprice pairs; i.e. $m=\left\{\left(X_{L}, Y_{L}\right),\left(X_{H}, Y_{H}\right)\right\}$ where the values of $\left(X_{L}, Y_{L}\right)$ and $\left(X_{H}, Y_{H}\right)$ are such that it is optimal for the buyer to select the option $\left(X_{L}, Y_{L}\right)$ if she is type- $L$ and $\left(X_{H}, Y_{H}\right)$ if she is type- $H$. Therefore, the supplier should design a mechanism under which a rational buyer will act according to her actual type. Zissis et al. (2015) prove Theorem 1 about the supplier's optimal strategy.

Theorem 1. The supplier designs the following quantity discount mechanism $m^{*}=$ $\left\{\left(X_{L}^{*}, Y_{L}^{*}\right),\left(X_{H}^{*}, Y_{H}^{*}\right)\right\}$ to minimize his cost:

i) if $f_{2}<f_{1} \leq 2$, then $X_{L}^{*}=Q_{J, L}^{*}, Y_{L}^{*}=C_{B, L}\left(Q_{J, L}^{*}\right)-C_{B, L}^{+}$,

$$
X_{H}^{*}=Q_{J, H}^{*}, Y_{H}^{*}=C_{B, H}\left(Q_{J, H}^{*}\right)-C_{B, H}^{+},
$$

ii) if $f_{2} \leq 2<f_{1}$, then $X_{L}^{*}=Q_{J, L}^{*}, Y_{L}^{*}=C_{B, L}\left(Q_{J, L}^{*}\right)-C_{B, L}^{+}$, 


$$
X_{H}^{*}=T, Y_{H}^{*}=C_{B, H}(T)-C_{B, H}^{+},
$$

iii) if $2<f_{2}<f_{1}$, then $X_{L}^{*}=Q_{J, L}^{*}, Y_{L}^{*}=C_{B, L}\left(Q_{J, L}^{*}\right)-C_{B, L}(W)+C_{B, H}(W)-C_{B, H}^{+}$,

$$
X_{H}^{*}=W, Y_{H}^{*}=C_{B, H}(W)-C_{B, H}^{+},
$$

where: $f_{1}=\sqrt{1+\frac{K_{S}}{K_{B}}}\left(1+\sqrt{\frac{h_{L}}{h_{H}}}\right), f_{2}=\sqrt{1-p} \sqrt{1+\frac{K_{S}}{K_{B}}} \frac{\sqrt{h_{L}}+\sqrt{h_{H}}}{\sqrt{h_{H}-p h_{L}}}, C_{B, L}^{+}=\sqrt{2 K_{B} D h_{L}}$, $C_{B, H}^{+}=\sqrt{2 K_{B} D h_{H}}, Q_{J, L}^{*}=\sqrt{2\left(K_{B}+K_{S}\right) D / h_{L}}, Q_{J, H}^{*}=\sqrt{2\left(K_{B}+K_{S}\right) D / h_{H}}$, $T=\frac{2 \sqrt{2 K_{B} D}}{\sqrt{h_{H}}+\sqrt{h_{L}}}$ and $W=\sqrt{\frac{2(1-p)\left(K_{B}+K_{S}\right) D}{h_{H}-p h_{L}}}$.

Note that, the buyer is free to participate in the mechanism $m^{*}$ and she decides to change her order quantity if and only if she ensures at least the same cost. The mechanism $m^{*}$ is in her self-interest, so she has an incentive to participate in the coordination mechanism. It is proven that the perfect coordination is feasible under incomplete information, which is the first case of Theorem 1 ; i.e. when $f_{2}<f_{1} \leq 2$.

Since this is a stochastic model due to the holding cost, which is a discrete random variable, we consider the expected number of trips per year. The latter is a function of the prior probability assessment pertaining to the low and the high values of holding cost with probability $p$ and $1-p$ respectively, and could be expressed as: $N\left(p, Q_{L}, Q_{H}\right)=$ $p D / Q_{L}+(1-p) D / Q_{H}$, where $Q_{L}$ and $Q_{H}$ are the order quantities when retailer is type- $L$ and type- $H$, respectively. Again, we use the particular case where the buyer has to decide her order quantity without discount as a benchmark. Therefore, the expected number of trips over a year when the supplier does not provide a discount is:

$$
N\left(p, Q_{B, L}^{*}, Q_{B, H}^{*}\right)=\sqrt{D / 2 K_{B}}\left(p \sqrt{h_{L}}+(1-p) \sqrt{h_{H}}\right)
$$

The order quantities under the coordination mechanism $m^{*}, X_{L}^{*}$ and $X_{H}^{*}$ are larger than $Q_{B, L}^{*}$ and $Q_{B, H}^{*}$. To evaluate the environmental performance of the coordination mechanism $m^{*}$, we make comparisons between the expected number of trips without discount and with the discount under the mechanism $m^{*}, N\left(p, X_{L}^{*}, X_{H}^{*}\right)$ for different parameter values that cover many applications in real-life business ventures. For brevity, 
we use $N\left(p, B^{*}\right)=N\left(p, Q_{B, L}^{*}, Q_{B, H}^{*}\right)$ and $N\left(p, m^{*}\right)=N\left(p, X_{L}^{*}, X_{H}^{*}\right)$. Therefore, the Equation 3, that measures the percentage reduction in the number of trips, becomes:

$$
I=\frac{N\left(p, B^{*}\right)-N\left(p, m^{*}\right)}{N\left(p, B^{*}\right)} \cdot 100 \%
$$

In line with Theorem 1, the percentage reduction in the number of trips per year $I$, can be calculated for the three different cases as follows:

$$
I= \begin{cases}1-\sqrt{\frac{K_{B}}{K_{S}+K_{B}}}, & \text { if } f_{2}<f_{1} \leq 2 \\ 1-\frac{p \sqrt{h_{L} K_{B}}}{\sqrt{K_{S}+K_{B}} \cdot\left(p \sqrt{h_{L}}+(1-p) \sqrt{h_{H}}\right)}-\frac{(1-p)\left(\sqrt{h_{L}}+\sqrt{h_{H}}\right)}{2\left(p \sqrt{h_{L}}+(1-p) \sqrt{h_{H}}\right)}, & \text { if } f_{2} \leq 2<f_{1} \\ 1-\sqrt{\frac{K_{S}}{K_{S}+K_{B}}} \cdot \frac{p \sqrt{h_{L}}+\sqrt{1-p} \sqrt{h_{H}-p h_{L}}}{p \sqrt{h_{L}}+(1-p) \sqrt{h_{H}}}, & \text { if } 2<f_{2}<f_{1}\end{cases}
$$

When perfect coordination is feasible under incomplete information (i.e. when $\left.f_{2}<f_{1} \leq 2\right)$, the indicator $I$ takes the same value with the case of complete information. This result is consistent with our intuition that the supplier in this case could provide the appropriate discounts to perfectly coordinate the chain. Therefore, the percentage reduction in the number of trips per year is the same as the case of complete information in which perfect coordination is achievable. For the other two cases (i.e. $f_{2} \leq 2<f_{1}$ and $\left.2<f_{2}<f_{1}\right)$ the coordination is not feasible, but under the mechanism $m^{*}$ a reduction in the number of trips per year is also achieved. The extent of reduction is based on the values of the model's parameters (Zissis et al., 2015).

A reduction in the frequency of deliveries brings other positive effects in addition to the reduction in fuel consumption and emissions such as a reduction in traffic nuisance, also lowering carbon emissions from all other vehicles, a reduction in the number of accidents, road fatalities, noise levels, and reduced transport times. All these effects are not simple to evaluate accurately, but they are significant to make supply chains sustainable.

Figure 1 depicts our work. As mentioned, the aim of this paper is to quantify the 
environmental impact of potential coordination on a decentralized two-node supply chain, using COPERT's emission model. The assessment is based on comparing the emissions and the fuel consumption that occur for different truck loads and speeds without and under coordination. The truck load is related to the coordination mechanism, while the different speeds indicate if the delivery trips between the buyer and the supplier are done in urban areas or not.

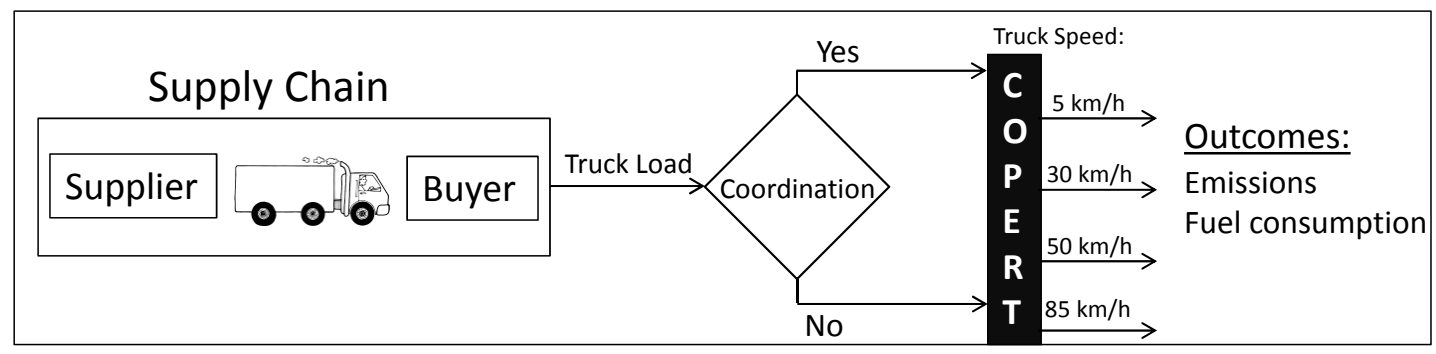

Figure 1: Work overview.

\section{Numerical Analysis}

In this section, we quantify the environmental impact of potential coordination between the nodes through the reduction of emissions and fuel consumption. We use numerical examples to cover a large range of parameter values concerning the fleet utilization and different speeds of the vehicles under complete and incomplete information. All numerical examples are coded and run in MATLAB R2015a.

It is noticeable that the order quantity is larger under the coordination mechanism $m^{*}$. This means that the frequency of deliveries between the nodes will be reduced when the nodes use the mechanism $m^{*}$, but at the same time the fleet utilization is increased, as the total volume per year of the transported product remains constant. It is interesting how the above factors affect the environment (emissions and fuel consumption) and the society (traffic nuisance, number of accidents, and noise levels), especially in urban areas, where the negative consequences are more intense. 


\subsection{Experiments Under Complete Information}

In this case where all parameters (i.e. $D, K_{B}, K_{S}$, and $H$ ) are constant and known to both nodes, the supplier has an incentive to coordinate the supply chain as is explained in Subsection 3.1. According to the Equation 3, the indicator $I$ is affected only by parameters $K_{B}$ and $K_{S}$. We consider 100 uniformly distributed values for each $K_{B}$ and $K_{S}$ in the following ranges: $K_{B} \in(50,100]$ and $K_{S} \in(50,250]$; i.e. the ratio of setup costs $K_{S} / K_{B}$ taking values in the range $(0.5,5]$ to measure the performance of coordination in terms of the percentage reduction in the number of trips per year. Therefore, we examine $10^{4}$ scenarios where the results are $41.2 \%$ average reduction in the number of trips per year, while the maximum reduction is $59 \%$ and the minimum is $18.9 \%$. Figure 2 shows how the percentage reduction in the number of trips is allocated among the $10^{4}$ examined scenarios in this experiment.

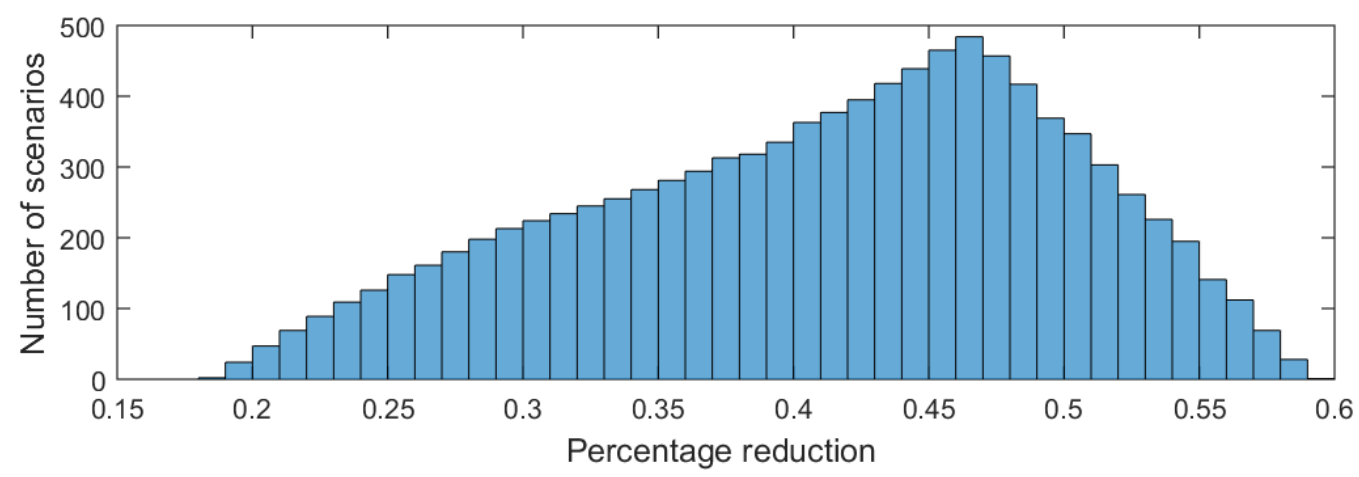

Figure 2: Percentage reduction in the number of trips.

We assume that the capacity of the vehicles which are used is equal to the optimal order quantity under coordination. This means that the vehicles are at full load (100\%) when the supplier provides the necessary discount to coordinate the chain. Moreover, if $K_{S}=3 K_{B}$ the optimal order quantity under coordination $Q_{J}^{*}$ is equal to $2 Q_{B}^{*}$. Therefore, the vehicle utilization will be raised from $50 \%$ to $100 \%$ and it would need exactly the half number of trips per year to meet the demand in comparison with the case in which the buyer decides the order quantity without having been offered a discount. Under the selection of these specific parameter values $\left(K_{S}=3 K_{B}\right)$ the vehicle utilization could 
be $0 \%, 50 \%$ and $100 \%$. Our choice of parameters is affected by the data availability, i.e. the parameters $a-f$ are available only for these loads and we are able to use the real parameter values without the need to estimate other intermediate values of vehicle loads. In the case of complete information, it is possible not using the regression model (Equation 2), assuming specific parameter values but the regression model is necessary in the case of incomplete information.

Table 4 presents the improvement in fuel consumption, $\mathrm{CO}, \mathrm{HC}, \mathrm{NO}_{\mathrm{x}}$, and $\mathrm{PM}$ emissions estimated by Equation 1 and Table 8 for given vehicle speeds in urban roads and highways. In line with Table 1, the improvement in $\mathrm{CO}_{2}$ emissions is the same as the improvement in fuel consumption. Note that, lower speeds $(\max 30 \mathrm{~km} / \mathrm{h})$ indicate that the transportation of goods takes place in urban areas, while on highways the speed range is from 50 to $80 \mathrm{~km} / \mathrm{h}$.

Table 4: Reduction in fuel consumption and emissions when $I=50 \%$ and the fleet utilization from $50 \%$ is raised to $100 \%$

\begin{tabular}{|c|c|c|c|c||c|c|}
\hline & \multicolumn{4}{|c||}{ Urban } & \multicolumn{2}{c|}{ Highway } \\
\hline Factor & $V=5$ & $V=10$ & $V=20$ & $V=30$ & $V=50$ & $V=80$ \\
\hline $\mathrm{FC}, \mathrm{CO}_{2}$ & $44.3 \%$ & $44.2 \%$ & $43.1 \%$ & $43.0 \%$ & $43.7 \%$ & $44.6 \%$ \\
\hline $\mathrm{CO}$ & $48.9 \%$ & $50.0 \%$ & $50.5 \%$ & $50.6 \%$ & $50.7 \%$ & $51.6 \%$ \\
\hline $\mathrm{HC}$ & $49.9 \%$ & $49.6 \%$ & $49.2 \%$ & $49.1 \%$ & $49.1 \%$ & $49.3 \%$ \\
\hline $\mathrm{NO}_{\mathrm{x}}$ & $55.7 \%$ & $54.9 \%$ & $53.7 \%$ & $52.9 \%$ & $51.2 \%$ & $48.0 \%$ \\
\hline $\mathrm{PM}$ & $49.2 \%$ & $49.4 \%$ & $48.7 \%$ & $48.6 \%$ & $48.6 \%$ & $48.9 \%$ \\
\hline
\end{tabular}

From Table 4, we can make the following observations:

1. The reduction in fuel consumption and emissions is at the same level to the reduction in the number of trips per year whilst some cases exceed the indicator $I$. In particular, the percentage reduction in $\mathrm{CO}$ emissions is higher than the percentage reduction in the number of trips per year when $V \geq 5 \mathrm{~km} / \mathrm{h}$ and the percentage reduction in $\mathrm{NO}_{\mathrm{x}}$ emissions is higher than the percentage reduction in the number of trips per year for all values of $V$ considered in the analysis. Note that when $K_{S}=3 K_{B}$, the percentage reduction in the number of trips per year is $50 \%$. Therefore, from Table 4 we can find the percentage fluctuation of fuel consumption and 
emission factors when $I=50 \%$.

2. Table 4 shows that the crucial factor for the environmental benefits is the number of trips per year (i.e. the total distance travelled) and not the vehicle loads for each trip, as the total volume per year of the transported product remains constant. This is the preferable case in the haulage companies, where the managers try to maximize the utilization of their vehicle fleet. The positive impact of this on the environment is evident in Table 4 .

3. The reduction in fuel consumption ranges from $43 \%$ to $45 \%$, but remains less than the $50 \%$, the percentage reduction in the number of trips per year, which could be considered an upper bound on the percentage reduction in fuel consumption. This result is consistent with our intuition that although we reduce the number of trips, the fuel consumed per travelled kilometre is higher due to the increased vehicle loads.

4. The reduction in $\mathrm{HC}, \mathrm{NO}_{\mathrm{x}}$, and $\mathrm{PM}$ emissions is closer to $50 \%$ than the reduction in fuel consumption. This happens because the emission factors are not too sensitive to the loads and depend almost exclusively on the total distance travelled, which is reflected in the number of trips in our case.

5. The HC and PM emissions do not vary with the vehicle speed, while the CO emissions are more sensitive to the vehicle speed. We observe that the reduction in $\mathrm{NO}_{\mathrm{x}}$ is a decreasing function of the vehicle speed due to many stop and go when the vehicle is travelling at lower speeds and this behavior is incorporated into the models estimating $\mathrm{NO}_{\mathrm{x}}$ emissions. The reduction in $\mathrm{CO}$ emissions is an increasing function (due to engine specifications) while the reduction fuel consumption, $\mathrm{CO}_{2}$, $\mathrm{HC}$ and PM emissions is decreasing at lower speeds and is increasing at higher ones. This happens because in urban environment with higher speed we have higher acceleration and deceleration for the same number of stop and go. Accelerating to higher maximum speed, the fuel consumption is higher compared to an acceleration in lower maximum speed. In the case of highways the opposite effect is observed because 
higher speed without stop-and-go's makes the vehicle perform better. Therefore, the minimum reduction in fuel consumption, $\mathrm{CO}_{2}, \mathrm{HC}$ and $\mathrm{PM}$ emissions is obtained in the vehicle speed range $[30,50]$, because in this speed range the engine efficiency is optimal. This means that the coordination mechanism $m^{*}$ contributes more under worse speed conditions (low and high speeds).

\subsection{Experiments Under Incomplete Information}

In this case, we assume that the buyer has private information of the holding cost $H$. As already explained in Subsection 3.2, we model the holding cost as a discrete random variable that could take two values. The buyer will be aware of the real value of $H$, while the supplier assumes only the prior probability assessment of the two values of the holding cost. The parameters $D, K_{B}$, and $K_{S}$ are constant and known to both nodes. We study two numerical examples to evaluate the environmental impact of coordination mechanism $m^{*}$ under incomplete information.

In the first numerical example, we consider 50 uniformly distributed values for each model parameter $K_{B}, K_{S}, h_{L}, h_{H}$, and $p$ in the following ranges: $K_{B} \in(50,150], K_{S} \in$ $(100,200], h_{L} \in(1,2], h_{H} \in(2,3], p \in(0,1)$. Therefore, we examine $3.125 \times 10^{8}$ scenarios to evaluate the performance of the coordination mechanism $m^{*}$, in terms of the percentage reduction in the number of trips per year between the nodes. We consider real life values of the parameters, where the ratio of holding costs $h_{H} / h_{L}$, i.e. the 'size' of the information asymmetry, takes values in the range $(1,3]$ (Becerril-Arreola et al., 2013). In this experiment, we obtain an average reduction of $24.3 \%$ in the number of trips per year while the maximum percentage reduction is $53.6 \%$ and the minimum is $0.7 \%$.

To further examine the performance of the coordination mechanism $m^{*}$ under more realistic cases where $K_{B}<K_{S}$, we consider the same experiment but now the parameters $K_{B}$ and $K_{S}$ take values in the ranges $K_{B} \in(50,100], K_{S} \in(200,300]$, i.e. the ratio of setup costs $K_{S} / K_{B}$ taking the values in the range $(2,6]$ (Zissis et al., 2015). In this case, the maximum percentage reduction in the number of trips per year is $60.8 \%$ 
while the average is $33 \%$ and the minimum is $1.1 \%$.

In the next numerical example, we consider six different scenarios that are presented in Table 5. For all the scenarios, it is assumed that supplier has no information available about the holding cost $H$. Therefore, it is uninformative for the low and high holding cost values; i.e. $p=1-p=1 / 2$. Two scenarios have been designed for each case in Theorem 1 ,

\section{Table 5: Experimental Setup}

\begin{tabular}{|c|c|c|c|c|c|c|c|}
\hline Scenario & $D$ & $K_{B}$ & $K_{S}$ & $h_{L}$ & $h_{H}$ & Case & Condition \\
\hline 1 & 5000 & 20 & 40 & 2 & 3 & iii & $2<f_{2}<f_{1}$ \\
\hline 2 & 10000 & 200 & 300 & 4 & 5 & iii & $2<f_{2}<f_{1}$ \\
\hline 3 & 5000 & 50 & 100 & 1 & 4 & ii & $f_{2} \leq 2<f_{1}$ \\
\hline 4 & 10000 & 100 & 100 & 1 & 3 & ii & $f_{2} \leq 2<f_{1}$ \\
\hline 5 & 5000 & 100 & 50 & 1 & 3 & i & $f_{2}<f_{1} \leq 2$ \\
\hline 6 & 10000 & 200 & 50 & 2 & 4 & i & $f_{2}<f_{1} \leq 2$ \\
\hline
\end{tabular}

We assume that the vehicle capacity is equal to the average order quantity under the coordination mechanism $m^{*}$, i.e. $p X_{L}^{*}+(1-p) X_{H}^{*}$. Therefore, the vehicle load when the buyer decides her order quantity without a discount from the supplier is $\frac{p Q_{B, L}^{*}+(1-p) Q_{B, H}^{*}}{p X_{L}^{*}+(1-p) X_{H}^{*}}$. Table 6 presents the results for the optimal order quantities with and without the coordination mechanism $m^{*}$ in terms of the buyer's low and high holding cost, the vehicle load, the expected number of trips $N\left(p, B^{*}\right), N\left(p, m^{*}\right)$ and the percentage reduction in the number of trips $(I)$.

Table 6: Comparison of results under six scenarios

\begin{tabular}{|c|r|r|c|r|r|r|r|c|}
\hline Scenario & \multicolumn{1}{|c|}{$Q_{B, L}^{*}$} & $Q_{B, H}^{*}$ & Load & $N\left(p, B^{*}\right)$ & \multicolumn{1}{|c|}{$X_{L}^{*}$} & $X_{H}^{*}$ & $N\left(p, m^{*}\right)$ & $I$ \\
\hline 1 & 316.2 & 258.2 & $61.4 \%$ & 17.59 & 547.7 & 387.3 & 11.02 & $37.3 \%$ \\
\hline 2 & 1000.0 & 894.4 & $66.0 \%$ & 10.59 & 1581.1 & 1291.0 & 7.04 & $33.6 \%$ \\
\hline 3 & 707.1 & 353.6 & $62.5 \%$ & 10.61 & 1224.7 & 471.4 & 7.34 & $30.7 \%$ \\
\hline 4 & 1414.2 & 816.5 & $73.5 \%$ & 9.66 & 2000.0 & 1035.3 & 7.33 & $24.1 \%$ \\
\hline 5 & 1000.0 & 577.4 & $81.7 \%$ & 6.83 & 1224.7 & 707.1 & 5.58 & $18.3 \%$ \\
\hline 6 & 1414.2 & 1000.0 & $89.4 \%$ & 8.54 & 1581.1 & 1118.0 & 7.63 & $10.6 \%$ \\
\hline
\end{tabular}

Assuming that: i) the regression model for interpolating fuel consumption from the three calculated parameter levels for 0\%, 50\%, and 100\% loads is valid (Equation 2), 
ii) the capacity of the EURO VI heavy-duty vehicle is equal to the average order quantity under the coordination mechanism $m^{*}$, and iii) each vehicle has two trips to (loaded with orders) and from (empty return) the buyer, we obtain the percentage reduction in the number of trips per year and fuel consumption for vehicle speed $V$ as presented in Table 7 estimated by Equations 1 and 2 .

Table 7: Percentage reduction in the number of trips and fuel consumption

\begin{tabular}{|c|c|r|r|r|r|r|r|}
\hline Scenario & $I$ & $V=5$ & $V=10$ & $V=20$ & $V=30$ & $V=50$ & $V=80$ \\
\hline 1 & $37.3 \%$ & $33.1 \%$ & $32.3 \%$ & $31.0 \%$ & $30.8 \%$ & $31.3 \%$ & $32.0 \%$ \\
\hline 2 & $33.6 \%$ & $29.6 \%$ & $28.9 \%$ & $27.7 \%$ & $27.5 \%$ & $27.9 \%$ & $28.6 \%$ \\
\hline 3 & $30.7 \%$ & $26.2 \%$ & $25.3 \%$ & $24.0 \%$ & $23.8 \%$ & $24.2 \%$ & $25.0 \%$ \\
\hline 4 & $24.1 \%$ & $20.6 \%$ & $20.0 \%$ & $19.0 \%$ & $18.9 \%$ & $19.2 \%$ & $19.8 \%$ \\
\hline 5 & $18.3 \%$ & $15.8 \%$ & $15.3 \%$ & $14.6 \%$ & $14.5 \%$ & $14.7 \%$ & $15.2 \%$ \\
\hline 6 & $10.6 \%$ & $9.0 \%$ & $8.7 \%$ & $8.3 \%$ & $8.2 \%$ & $8.3 \%$ & $8.6 \%$ \\
\hline
\end{tabular}

As we observe the percentage reduction in the number of trips per year $(I)$ is an indicator of both the reduction in fuel consumption and the emission factors under complete and incomplete information. In all scenarios, the indicator $I$ is an upper bound on the fuel consumption for all vehicle speeds included in the experiment. The highest reduction in fuel consumption is achieved in the third case of Theorem 1 (Scenario 1 and 2), where the economical benefits based on mechanism $m^{*}$ are more significant than in the other cases (Zissis et al., 2015). The lowest reductions in fuel consumption are obtained in the first case of Theorem 1 (Scenario 5 and 6) where the mechanism $m^{*}$ coordinates the supply chain, in which the indicator $I$ takes the lowest values.

We show that there are models in which it is possible to achieve a simultaneous reduction on the economic and environmental costs on logistics activities. This means that cost reduction could be environmentally friendly, as it is presented in a different framework by (Fleischmann et al., 2003) about the IBM case. Of course, we do not claim that the optimal solution for the environment always decreases the cost, as we have seen in the work by Cachon (2014) about the retail store density problem. In our model, the crucial factor for the environmental benefits is the total distance travelled (i.e. the number of trips) and not the vehicle loads, since the total volume of the transported product is 
kept constant $(D)$. Hence, via a more efficient management of the order quantities could achieve both economic and environmental benefits.

\section{Conclusions}

In this paper, we considered a two-node supply chain with one supplier producing a single product in a lot-for-lot fashion and one buyer, who orders and stores the same product in fixed quantities. Both nodes are rational and make private decisions; the buyer decides the lot size and the supplier decides the quantity discount. We experimented with a quantity discount mechanism to coordinate the chain and reduce the operational costs. According to our intuition a coordination mechanism increases the order size and subsequently decreases the frequency of deliveries. We quantified the environmental impact of coordination through numerical examples that incorporated the COPERT emission model and justified the environmental gains from coordination.

The numerical examples demonstrated that the reduction in fuel consumption and emission factors is close to the indicator that measures the reduction in the number of trips under complete and incomplete information. For realistic parameter values the average improvement is at least $20 \%$ in comparison to the case without any kind of coordination between the nodes. Therefore, it is shown that a more efficient management of the order quantities except for the cost reduction could raise the environmental gains in terms of reduced emissions while the number of delivered items remains the same.

Potential extensions of our work include the study of multi-product supply chains with additional nodes and advanced coordination mechanisms such as sales rebate and two-part tariffs. Moreover, it is worth studying the cases of air and sea transportation and then comparing the results with the case of road transportation. An important aspect is to make an assumption about the node that bears the major part of the transportation expenses and how this affects both the coordination mechanism and its environmental impact. Furthermore, the design of a mechanism to optimize the environmental gains 
and examine how the mechanism affects the nodes' costs can be compared to the base case where the mechanism is designed exclusively to minimize the nodes' operational costs.

\section{Acknowledgments}

We are indebted to the anonymous referee and Associate Editor, Prof. Kevin Cullinane, for their comments and suggestions that helped improve the context and the presentation

of the material in the paper. This research has been financed by the Athens University of Economics and Business through the Research Support Program 2016 - 2017, Action 2: Support to Postdoctoral Researchers.

\section{Appendix}

We have used the following notation throughout the paper: 
Variables

D

$K_{S}, K_{B}$

$H=\left\{h_{L}, h_{H}\right\}$

$p$

$Q$

$Q_{B}^{*}=\left\{Q_{B, L}^{*}, Q_{B, H}^{*}\right\}$

$Q_{J}^{*}=\left\{Q_{J, L}^{*}, Q_{J, H}^{*}\right\}$

$(X, Y)=\left\{\left(X_{L}, Y_{L}\right),\left(X_{H}, Y_{H}\right)\right\}$

$\left(X_{L}^{*}, Y_{L}^{*}\right),\left(X_{H}^{*}, Y_{H}^{*}\right)$

$C_{S}(\cdot)$

$C_{B}(\cdot)=\left\{C_{B, L}(\cdot), C_{B, H}(\cdot)\right\}$

I

$N(\cdot)$

V

$E F(V)$

$x$

$F C(x)$
Definition

Annual market demand

Supplier's, buyer's setup cost

Holding cost (low, high)

Probability of low holding cost

Order quantity or lot size (buyer's decision)

Optimal lot size without discount (low, high)

System's optimal lot size (low, high)

Quantity discount (supplier's decision, low, high)

Supplier's optimal decisions (low, high)

Supplier's cost function

Buyer's cost function (low, high)

Reduction (\%) of the annual number of trips

Expected number of trips per year

Vehicle speed in $\mathrm{km} / \mathrm{h}$

Output from COPERT 5 based on vehicle speed $V$

Vehicle load as percentage

Fuel consumption based on vehicle load $x$ 
Table 8: Emission factors for EURO VI heavy-duty vehicle (g/km)

\begin{tabular}{|l|c|c|c|c|c|c|c|c|}
\hline Factor & Load & $\mathrm{a}$ & $\mathrm{b}$ & $\mathrm{c}$ & $\mathrm{d}$ & $\mathrm{e}$ & $\mathrm{f}$ & $\mathrm{g}$ \\
\hline \multirow{3}{*}{$\mathrm{CO}$} & $0 \%$ & $-1.58 \mathrm{E}-04$ & $-2.74 \mathrm{E}-02$ & $4.01 \mathrm{E}+00$ & $-5.01 \mathrm{E}+00$ & $-8.06 \mathrm{E}-03$ & $7.14 \mathrm{E}-01$ & $7.06 \mathrm{E}-01$ \\
& $50 \%$ & $-1.58 \mathrm{E}-04$ & $-2.78 \mathrm{E}-02$ & $3.90 \mathrm{E}+00$ & $-4.82 \mathrm{E}+00$ & $-8.21 \mathrm{E}-03$ & $7.21 \mathrm{E}-01$ & $3.94 \mathrm{E}-01$ \\
& $100 \%$ & $-1.36 \mathrm{E}-04$ & $-2.02 \mathrm{E}-02$ & $2.96 \mathrm{E}+00$ & $-3.78 \mathrm{E}+00$ & $-6.58 \mathrm{E}-03$ & $5.79 \mathrm{E}-01$ & $0.00 \mathrm{E}+00$ \\
\hline \multirow{3}{*}{$\mathrm{HC}$} & $0 \%$ & $7.34 \mathrm{E}-04$ & $1.14 \mathrm{E}-01$ & $1.68 \mathrm{E}+00$ & $-6.88 \mathrm{E}-01$ & $9.23 \mathrm{E}-02$ & $1.90 \mathrm{E}+00$ & $1.00 \mathrm{E}-08$ \\
& $50 \%$ & $4.24 \mathrm{E}-04$ & $7.96 \mathrm{E}-02$ & $1.41 \mathrm{E}+00$ & $-4.93 \mathrm{E}-01$ & $5.58 \mathrm{E}-02$ & $1.63 \mathrm{E}+00$ & $0.00 \mathrm{E}+00$ \\
& $100 \%$ & $4.15 \mathrm{E}-04$ & $1.01 \mathrm{E}-01$ & $1.64 \mathrm{E}+00$ & $-4.59 \mathrm{E}-01$ & $6.33 \mathrm{E}-02$ & $1.96 \mathrm{E}+00$ & $4.00 \mathrm{E}-08$ \\
\hline \multirow{3}{*}{$\mathrm{PM}$} & $0 \%$ & $1.67 \mathrm{E}-03$ & $1.63 \mathrm{E}-01$ & $-6.70 \mathrm{E}-03$ & $6.33 \mathrm{E}-01$ & $1.32 \mathrm{E}+00$ & $4.66 \mathrm{E}-01$ & $3.03 \mathrm{E}-01$ \\
& $50 \%$ & $1.66 \mathrm{E}-03$ & $1.90 \mathrm{E}-01$ & $-1.17 \mathrm{E}-01$ & $4.92 \mathrm{E}-01$ & $1.37 \mathrm{E}+00$ & $4.75 \mathrm{E}-01$ & $3.21 \mathrm{E}-01$ \\
& $100 \%$ & $1.12 \mathrm{E}-03$ & $1.54 \mathrm{E}-01$ & $-2.60 \mathrm{E}-01$ & $1.08 \mathrm{E}+00$ & $9.83 \mathrm{E}-01$ & $5.91 \mathrm{E}-01$ & $2.50 \mathrm{E}-01$ \\
\hline \multirow{3}{*}{$\mathrm{NO}$} & $0 \%$ & $-8.45 \mathrm{E}-04$ & $1.41 \mathrm{E}-01$ & $-6.92 \mathrm{E}-01$ & $1.82 \mathrm{E}+00$ & $5.65 \mathrm{E}-03$ & $-3.35 \mathrm{E}-02$ & $6.87 \mathrm{E}-02$ \\
& $50 \%$ & $-9.32 \mathrm{E}-06$ & $6.47 \mathrm{E}-02$ & $-4.57 \mathrm{E}-01$ & $1.93 \mathrm{E}+00$ & $5.51 \mathrm{E}-03$ & $-3.57 \mathrm{E}-02$ & $8.00 \mathrm{E}-02$ \\
\multirow{2}{*}{ Fuel } & $100 \%$ & $3.42 \mathrm{E}-04$ & $5.44 \mathrm{E}-02$ & $-4.11 \mathrm{E}-01$ & $1.75 \mathrm{E}+00$ & $6.65 \mathrm{E}-03$ & $-4.04 \mathrm{E}-02$ & $8.14 \mathrm{E}-02$ \\
Consumption & $0 \%$ & $2.45 \mathrm{E}-02$ & $4.51 \mathrm{E}-01$ & $3.08 \mathrm{E}+00$ & $7.90 \mathrm{E}+00$ & $2.03 \mathrm{E}-04$ & $-6.45 \mathrm{E}-04$ & $9.84 \mathrm{E}-03$ \\
& $50 \%$ & $4.31 \mathrm{E}-02$ & $1.49 \mathrm{E}+00$ & $-3.91 \mathrm{E}+00$ & $8.94 \mathrm{E}+00$ & $3.17 \mathrm{E}-04$ & $-6.90 \mathrm{E}-04$ & $4.19 \mathrm{E}-03$ \\
& $100 \%$ & $3.16 \mathrm{E}-02$ & $1.66 \mathrm{E}+00$ & $-4.84 \mathrm{E}+00$ & $5.82 \mathrm{E}+00$ & $2.17 \mathrm{E}-04$ & $1.18 \mathrm{E}-04$ & $0.00 \mathrm{E}+00$ \\
\hline
\end{tabular}




\section{References}

Achour, H. and Olabi, A. G. (2016). Driving cycle developments and their impacts on energy consumption of transportation. Journal of Cleaner Production, 112:1778-1788.

Ajtay, D. (2005). Modal Pollutant Emissions Model of Diesel and Gasoline Engines. PhD thesis, Swiss federal institute of technology, Zurich, Ramistrasse 101, 8092 Zurich, Switzerland.

Altintas, N., Erhyn, F., and Tayur, S. (2008). Quantity discounts under demand uncertainty. Management Science, 54(4):777-792.

Becerril-Arreola, R., Leng, M., and Parlar, M. (2013). Online retailers' promotional pricing, free-shipping threshold, and inventory decisions: A simulation-based analysis. European Journal of Operational Research, 230(2):272-283.

Bektas, T. and Laporte, G. (2011). The pollution-routing problem. Transportation Research Part B: Methodological, 45(8):1232-1250.

Boulter, P., McCrae, I. S., and Barlow, T. J. (2007). A review of instantaneous emission models for road vehicles. Technical report, Transport Research Laboratory. https: //docs.niwa.co.nz/library/public/PPR267.pdf.

Burnetas, A., Gilbert, S., and Smith, C. (2007). Quantity discounts in a single-period supply contracts with asymmetric demand information. IIE Transactions, 39(5):465479 .

Cachon, G. P. (2014). Retail store density and the cost of greenhouse gas emissions. Management Science, 60(8):1907-1925.

Cen, X., Lo, H. K., and Li, L. (2016). A framework for estimating traffic emissions: The development of passenger car emission unit. Transportation Research Part D: Transport and Environment, 44:78 - 92 . 
Chen, S.-C., Cardenas-Barron, L. E., and Teng, J.-T. (2014). Retailer's economic order quantity when the supplier offers conditionally permissible delay in payments link to order quantity. International Journal of Production Economics, 155:284 - 291.

CIVITAS (2015). Policy note: Making urban freight logistics more sustainable. Technical report, CIVITAS WIKI consortium. http://www.eltis.org/sites/eltis/files/ trainingmaterials/civ_pol-an5_urban_web-1.pdf.

Corbett, C. (2001). Stochastic inventory systems in a supply chain with asymmetric information: Cycle stocks, safety stocks, and consignment stock. Operations Research, $49(4): 487-500$.

Corbett, C., Zhou, D., and Tang, C. (2004). Designing supply contracts: Contract type and information asymmetry. Management Science, 50(4):550-559.

COST (2006). Emissions and fuel consumption from heavy duty vehicles. Technical report, Graz University of Technology. http://http://www.transport-research. info/sites/default/files/project/documents/20090619_171415_76456_I_ COST346_FinalReport.pdf.

de Haan, P. and Keller, M. (2000). Emission factors for passenger cars: application of instantaneous emission modeling. Atmospheric Environment, 34(27):4629 - 4638.

Demir, E., Bektas, T., and Laporte, G. (2014). A review of recent research on green road freight transportation. European Journal of Operational Research, 237(3):775-793.

EC (2011). DG for mobility and transport: Road freight transport vademecum. Technical report, European Commission. http://ec.europa.eu/transport/modes/road/doc/ 2010-road-freight-vademecum.pdf.

EC (2015). EU transport in figures, statistical pocketbook. Technical report, European Commission. https://ec.europa.eu/transport/sites/transport/ files/pocketbook2015.pdf. 
EEA (2016). EMEP/EEA air pollutant emission inventory guidebook. Technical report, European Environment Agency. http://www.eea.europa.eu//publications/ emep-eea-guidebook-2016.

EPA (2015). Sources of greenhouse gas emissions. Technical report, United States Environmental Protection Agency. https://www.epa.gov/ghgemissions/ sources-greenhouse-gas-emissions

Faris, W., Rakha, H., Kafafy, R. I., Idres, M., and Elmoselhy, S. (2011). Vehicle fuel consumption and emission modelling: an in-depth literature review. International Journal of Vehicle Systems Modelling and Testing, 6(3-4):318-395.

Fleischmann, M., van Nunen, J. A. E. E., and Grave, B. (2003). Integrating closed-loop supply chains and spare-parts management at IBM. Interfaces, 33(6):44-56.

Fudenberg, D. and Tirole, J. (1991). Game theory. Massachusetts Institute of Technology.

Hervani, A., Helms, M., and Sarkis, J. (2005). Performance measurement for green supply chain management. Benchmarking: An International Journal, 12(4):330-353.

Lovejoy, W. S. (2006). Optimal mechanisms with finite agent types. Management Science, $52(5): 788-803$.

Myerson, R. (1991). Game Theory: Analysis of Conflict. Harvard University Press.

Nagarajan, M. and Sosic, G. (2008). Game-theoretic analysis of cooperation among supply chain agents: Review and extensions. European Journal of Operational Research, 187(3):719- 745 .

Neto, J. Q. F., Bloemhof-Ruwaard, J., van Nunen, J., and van Heck, E. (2008). Designing and evaluating sustainable logistics networks. International Journal of Production Economics, 111(2):195-208. 
Park, S., Lee, J., and Lee, C. (2016). State-of-the-art automobile emissions models and applications in North America and Europe for sustainable transportation. KSCE Journal of Civil Engineering, 20(3):1053-1065.

RITA (2010). Freight transportation: Global highlights. Technical report, US Department of Transportation. https://www.rita.dot.gov/bts/sites/rita.dot.gov. bts/files/publications/freight_transportation/pdf/entire.pdf

Sarkis, J., Helms, M., and Hervani, A. (2010). Reverse logistics and social sustainability. Corporate Social Responsibility and Environmental Management, 17:337-354.

Shao, J., Yang, H., Xing, X., and Yang, L. (2016). E-commerce and traffic congestion: An economic and policy analysis. Transportation Research Part B: Methodological, 83:91 103.

Smit, R., Smokers, R., and Rab, E. (2007). A new modelling approach for road traffic emissions: Versit+. Transportation Research Part D: Transport and Environment, 12(6):414 $-422$.

Sundarakani, B., de Souza, R., Goh, M., Wagner, S. M., and Manikandan, S. (2010). Modeling carbon footprints across the supply chain. International Journal of Production Economics, 128(1):43-50.

Szeto, W. Y., Jaber, X., and Wong, S. C. (2012). Road network equilibrium approaches to environmental sustainability. Transport Reviews, 32(4):491-518.

Viswanathan, S. and Wang, Q. (2003). Discount pricing decisions in distribution channels with price sensitive demand. European Journal of Operational Research, 149(3):571587.

Zissis, D., Ioannou, G., and Burnetas, A. (2015). Supply chain coordination under discrete information asymmetries and quantity discounts. Omega, 53:21-29. 